\title{
CAPTAÇÃO DE RECURSOS NA ONG " $X "$ ": UMA EXPERIÊNCIA PRÁTICA INTERDISCIPLINAR ENTRE PROFISSIONAIS ADMINISTRAÇÃO E SECRETARIADO EXECUTIVO
}

\author{
FUNDRAISING IN ONG "X": \\ INTERDISCIPLINARY PRACTICE BETWEEN AN EXPERIENCE \\ PROFESSIONAL ADMINISTRATION AND EXECUTIVE SECRETARY
}

\section{Juliane Sachser Angnes}

Professora da Universidade Estadual do Centro Oeste do Paraná - UNICENTRO

Doutora na área de Educação pela Universidade Federal do Paraná - UFPR

julianeangnes@gmail.com

\section{Mábia Camargo}

Professora no curso de graduação em Secretariado Executivo na Universidade Estadual do Centro-Oeste - UNICENTRO

Mestranda em Linguagem, Identidade e Subjetividade na Universidade Estadual de Ponta Grossa - UEPG

mabiacamargo@hotmail.com

\section{Luciano Ferreira de Lima}

Professor no curso de Administração da Universidade Estadual do Centro-Oeste UNICENTRO

Mestre em Ciências Sociais Aplicadas pela Universidade Estadual de Ponta Grossa - UEPG prof.luciano@ymail.com

\section{Marcel Luciano Klozovski}

Professor no curso de Administração da Universidade Estadual do Centro-Oeste UNICENTRO

Mestrando em Contabilidade e Finanças da Universidade Federal do Paraná - UFPR marcel73 adm-fin-log@hotmail.com 


\section{RESUMO}

Este artigo apresenta resultados parciais de um projeto de pesquisa, com enfoque interdisciplinar, realizado em parceria por professores dos cursos de Administração e Secretariado Executivo da Universidade Estadual do Centro Oeste do Paraná (Unicentro), no ano de 2011. Ele se propôs auxiliar, a partir da realidade local, na elaboração de um plano para captação de recursos destinado a ONG " $X$ ", localizada na cidade de Guarapuava-PR, uma vez que desde o ano de 2006 houve uma redução dos recursos investidos pelos principais financiadores Agências de Cooperação Internacional - nesta organização. Trata-se de uma pesquisa qualitativa com proposição de planos, que utilizou a pesquisa bibliográfica, documental e a observação participante seguida de reuniões com o dirigente e funcionários da ONG como principais técnicas de pesquisa. Observouse que a organização depende quase que integralmente dos recursos captados junto às fontes externas e, no entanto, não possui efetivamente ações planejadas de captação de recursos. Por sua vez, o estudo empírico demonstrou que há possibilidade de se ampliar as fontes e possibilidades de captação de recursos para esta ONG na região de Guarapuava desde que se tenha um projeto bem estruturado. Desta maneira, observou-se a relevância em se trabalhar interdisciplinarmente, visto que a área de assessoria permite um esforço coordenado de várias disciplinas em torno de um objetivo comum que, neste estudo, se configura uma proposição na área de Responsabilidade Social.

Palavras-chave: Captação de Recursos; Responsabilidade Social; ONGs. 


\section{ABSTRACT}

This article presents partial results of a research project, with an interdisciplinary focus, conducted in partnership with teachers of the courses of Administration and Executive Secretary of the Universidade Estadual do Centro Oeste do Paraná (Unicentro), in 2011, which was proposed auxiliary from the local reality, in developing a plan for fundraising for the ONG "X" located in Guarapuava-PR, since from the year 2006 there was a reduction of resources invested by major donors - Cooperation Agencies International - in this organization. This is a qualitative research proposal of plans, which used the bibliographical research and participant observation followed by meetings with the manager and employees of ONGs as major research techniques. It was felt that this organization depends almost entirely on funds raised from external sources, however, has not effectively planned actions fundraising. In turn, the empirical study showed that there is possibility to expand the sources and possibilities of raising funds for ONGs in this region Guarapuava provided that it is good, structured design. Thus, it was noted the relevance of interdisciplinary work, since the area of advice allows a coordinated effort of several disciplines around a common goal, that this study sets up a proposition in the area of Social Responsibility.

Keywords: Fundraising; Social Responsibility; ONGs. 
Juliane Sachser Angnes, Mábia Camargo, Luciano Ferreira de Lima \& Marcel Luciano

\section{INTRODUÇÃO}

De acordo com Farias (2008), a partir do novo modelo econômico que aumentou o poder de privados nacionais e internacionais, percebe-se na sociedade vigente o aumento das desigualdades, o alastramento da corrupção, o abandono da ideia de solidariedade e o negligenciamento do exercício da cidadania.

A partir desse contexto, observou-se, nos últimos anos, a ampliação do denominado Terceiro Setor, tanto em contexto internacional, como em contexto brasileiro. Ou seja, Terceiro Setor aparece como ator principal e suas coadjuvantes são as Organizações sem Fins Lucrativos - denominadas ONGs nascidas da iniciativa voluntária que mobilizam a sociedade para trabalhar em parceria com os setores públicos e privados, tornando-se um agente social de desenvolvimento. (RODRIGUES, 1998 apud ANDRADE, 2002, p. 34)

Para Andrade (2002) um dos maiores desafios das ONGs no Brasil é a sua sustentabilidade a médio e longo prazo, e uma das alternativas para tal problema é a captação de recursos financeiros, bem como a diversificação de fontes para a captação deles. Para isso, tanto quanto as empresas privadas, as ONGs também necessitam de planos estratégicos e profissionais competentes, multifuncionais e aptos para trabalhar neste contexto.

Dito de outra forma, o contexto atual internacional evidencia crises, situações de colapso e regressões em países como a África e países Islâmicos, por exemplo. Uma das consequências dessas situações passa a ser a mudança de foco por parte das Agências de Cooperação Internacional, em relação ao destino de seus recursos financeiros. Ou seja, os recursos financeiros estão sendo destinados para países considerados em situação de emergência, e o Brasil é classificado fora dessa situação. (RITS, 2011)

Em contraponto, o Brasil apresenta problemas internos graves, como a má distribuição de renda, corrupção, pobreza, dentre outros. Porém, esses problemas são considerados como fatores internos pelas Agências de Cooperação Internacionais, não mais afetando a "bondade" dessas agências, que focam desde 2006, seus recursos financeiros para a África, Leste Europeu e uma 
pequena parcela, por que não dizer "migalhas", destinada ao norte brasileiro. (ABONG, 2010, p. 67)

Como parte envolvida nesta mudança de investimentos financeiros, encontra-se a ONG " $X$ ", uma organização de médio porte, localizada na cidade de Guarapuava-PR, que serviu como locus empírico para esta pesquisa. Nessa ONG, a maior parte recursos financeiros (receita) dependia das Agências de Cooperação Internacional, e atualmente houve uma redução do investimento pelos fatores já mencionados. Neste sentido, a demanda por estratégias de captação de recursos tornou-se algo evidente e urgente para sobrevivência da instituição.

Dessa forma, por meio das observações participativas nesta pesquisa, bem como estudos referentes ao Terceiro Setor e suas estratégias de captação de recursos no Brasil, constatou-se que a ONG " $X$ " não possuía um plano estruturado que fosse exclusivamente destinado à captação de recursos, nem tampouco a sistematização deles.

Sendo assim, este artigo propõe como objetivo geral descrever o processo de elaboração de um plano de captação de recursos para a ONG " $X$ ", localizada na cidade de Guarapuava-PR. Cabe destacar, que o estudo realizado partiu das necessidades específicas da ONG "X", não sendo uma "receita mágica" que possa apresentar os mesmos resultados em outras ONGs. Ainda assim, a descrição dos resultados pode ser representativa em outras realidades, desde que se leve em consideração seu contexto específico.

Destaca-se, ainda, que a pesquisa realizada teve limitações no âmbito da pesquisa bibliográfica, utilizando-se de referências disponíveis e selecionadas pelos pesquisadores, mas não pretendendo dar conta de todo universo publicado referente às ONGs no Brasil. Também, teve limitações quanto à publicação de dados financeiros da ONG " $X$ " e da lista de potenciais financiadores/doadores na região de Guarapuava como forma de preservação ética dos sujeitos envolvidos na pesquisa. 
Juliane Sachser Angnes, Mábia Camargo, Luciano Ferreira de Lima \& Marcel Luciano

\section{REFERENCIAL TEÓRICO}

\subsection{TERCEIRO SETOR: CONTEXTUALIZAÇÃO}

No Brasil, assim como em outros países, ocorreu nos últimos anos o crescimento do denominado Terceiro Setor que, por sua vez, coexiste com dois outros setores: a) Primeiro Setor, representado pelo governo, cumprindo este uma função administrativa dos bens públicos, correspondendo assim às ações do Estado com fins públicos, tanto no âmbito municipal, estadual como federal, e b) Segundo Setor, representado pelo mercado, ocupado pelas empresas privadas com fins lucrativos. (DELGADO, 2004)

Cabe destacar que segundo a autora citada, há algo em comum entre o Primeiro Setor (Estado) e o Terceiro Setor: ambos devem cumprir uma função eminentemente coletiva. Assim, no Terceiro Setor agrupam-se uma grande variedade de instituições: Organizações Não Governamentais, Fundações e Institutos Empresariais, Associações Comunitárias, Entidades Assistenciais e Filantrópicas, assim como várias outras instituições sem fins lucrativos.

No que tange a questão conceitual, referente ao Terceiro Setor, observase não haver consenso por parte dos estudiosos sobre o tema. Desta forma, coexistem diversas definições. Para Fernandes o Terceiro Setor é:

Um conjunto de organizações e iniciativas privadas que visam à produção de bens e serviços públicos. Este é o sentido positivo da expressão. "Bens e serviços públicos", nesse caso implicam uma dupla qualificação: não geram lucros e respondem a necessidades coletivas. (FERNANDES, 1994, p. 21)

Por sua vez, para Rothgiesser (2011, p. 2), Terceiro Setor seriam iniciativas "... privadas que não visam lucros, iniciativas na esfera pública que não são feitas pelo Estado. São cidadãos participando de modo espontâneo e voluntário, em ações que visam ao interesse comum." Percebe-se por meio das conceituações que o Terceiro Setor é classificado como aquele que possui atuação em uma esfera de atuação pública, não estatal, formada a partir de iniciativas voluntárias, sem fins lucrativos, no sentido comum.

Neste sentido, Cury (1999), ressalta que a sociedade civil se organiza por meio do Terceiro Setor, das Organizações Socialmente Responsáveis, das 
Captação de recursos na ONG " $X$ ":

Uma experiência prática interdisciplinar entre profissionais administração e secretariado executivo

Organizações Sociais, das Fundações, ONGs e Associações e volta-se para a melhoria da qualidade de vida com a elaboração de projetos, iniciativas, parcerias, pesquisas e campanhas que vêm transformando em todo o mundo o paradigma de ação social. Segundo Abong:

A expressão Terceiro Setor, também constantemente utilizada para referir-se às organizações da sociedade civil sem fins lucrativos de uma forma em geral, abriga, além das ONGs, outros segmentos com identidades diversas, como entidades filantrópicas e institutos empresariais. (ABONG, 2010, p. 5)

Observa-se na citação anterior que a ideia de Terceiro Setor, para Abong (2010), é o universo no qual as ONGs se localizam, onde se encontram as entidades sem fins lucrativos. De acordo com Rockefeller (1993) apud Abong (2010, p. 115) o Terceiro Setor é como um "setor invisível" e torna-se cada dia mais indispensável na sociedade. Para este autor todas as entidades - igrejas, hospitais, museus, bibliotecas, universidades e escolas privadas, grupos de teatros, orquestras sinfônicas e organizações de assistência social - constituem o Terceiro Setor e conclui "que todos os movimentos contemporâneos cresceram dele, como os direitos civis, defesa de consumidores, direitos das mulheres, ambientalismo e muitos outros." (Op. cit. , p. 115)

Cabe destacar que expressão ONG foi criada pela ONU na década de 1940 para designar entidades não oficiais que recebiam ajuda financeira de órgãos públicos para executar projetos de interesse social. O Banco Mundial definiu as ONGs como grupos de instituições que são inteiramente ou largamente independentes do governo e caracterizadas principalmente por objetivos humanitários e corporativos, em vez de comerciais (KORTEN apud GONH, 2000).

Por sua vez, no Brasil, as ONGs originaram-se da participação das entidades sem fins lucrativos datada no final do século XIX. Como exemplo dessas entidades menciona-se as Santas Casas que remontam a partir da segunda metade do século XVI, e trazem consigo uma tradição da presença das igrejas cristãs que direta ou indiretamente atuavam prestando assistência às comunidades. Também, tem-se como exemplo a Igreja Católica, que com o suporte do Estado, era responsável pela maior parte das entidades que "prestavam algum tipo de assistência às comunidades mais necessitadas, que ficavam às margens das políticas sociais básicas de saúde e educação. A atuação 
Juliane Sachser Angnes, Mábia Camargo, Luciano Ferreira de Lima \& Marcel Luciano

das Igrejas, concomitante com o Estado, durou todo o período colonial, até início do século XIX." (RELATÓRIO GESET, 2010, p. 6-7)

Já no século $X X$, surgiram outras religiões, que juntamente com a Igreja Católica, passaram a atuar no campo da caridade com fins filantrópicos associadas ao Estado. Entretanto, no período republicano, a relação Igreja e Estado mudou, uma vez que antes esses dois objetivavam o atendimento e a assistência das questões sociais. Nessa nova fase, passaram a atuar outras religiões, utilizando-se das mesmas práticas da Igreja Católica, beneficiando-se também, de parcerias com fins filantrópicos junto ao Estado. (RELATÓRIO GESET, 2010, p. 6). De acordo com Delgado:

Além da introdução de novas instituições atuando em setores que até então tinham a atuação de atores tradicionais, um outro fator que colaborou para essa mudança de relacionamento entre a Igreja e o Estado foi a modernização natural da própria sociedade, fruto da industrialização e urbanização da época, fazendo com que aumentasse a complexidade dos problemas sociais. (DELGADO, 2004, p. 34)

A partir deste contexto, começaram a surgir na década de 1930 várias entidades da sociedade civil, sendo a maioria delas também atreladas ao Estado. O Estado Novo deu continuidade ao processo de criação de organizações de finalidade pública. Ainda nesse período, cresceu o número de entidades atuando no Terceiro Setor, cuja representatividade já não era tão definida, ou seja, não se tratava mais só de Igrejas e Estado, mas também, de entidades não governamentais, sem fins lucrativos e de finalidade pública. (RELATÓRIO GESET, 2010, p. 6-7)

Por sua vez, nas décadas de 1970 e 1980 se acentua uma sociedade tradicionalmente hierarquizada e desigual e começam a surgir movimentos sociais, opondo-se especialmente às práticas autoritárias do regime militar desse período, assim como reivindicando direitos sociais. (GOHN, 2000)

Como consequência de um amplo processo de mobilização social, a nova Constituição de República Federativa do Brasil, em 1988, promoveu melhorias no que diz respeito ao aumento dos direitos de cidadania política e princípios da descentralização na promoção de políticas sociais. Adicionalmente, houve muitas pressões dos movimentos populares, por meio dos chamados "lobbies populares" no congresso, a fim de que emendas populares fossem aprovadas. Desta forma, 
Captação de recursos na ONG " $X$ ": Uma experiência prática interdisciplinar entre profissionais administração e secretariado executivo

"torna-se inegável que a Nova Constituição representou um avanço no que diz respeito a política social no Brasil." (TEIXEIRA, 2000, p. 31 apud DELGADO, 2004, p. 65)

Neste contexto, constatou-se nas últimas décadas um crescimento quantitativo e qualitativo do Terceiro Setor como um todo, em especial das ONGs (Organizações Não Governamentais). Em outras palavras, esse crescimento ocorreu por meio da consolidação democrática, das pluralidades partidárias, formação de sindicatos e fortalecimentos de movimentos sociais urbanos e rurais, abrindo-se espaço para uma atuação mais efetiva das ONGs.

Complementando, Gonçalves citado por Delgado (2004) justifica tal crescimento da seguinte forma:

Em virtude da atuação ineficiente do Estado, em especial na área social, o Terceiro Setor vem crescendo e se expandindo em várias áreas, objetivando atender a demanda por serviços sociais, requisitados por uma quantidade expressiva da população menos favorecida, em vários sentidos, de que o Estado e os agentes econômicos não têm interesses ou não são capazes de provê-la. Seu crescimento vem em virtude, também, de práticas cada vez mais efetivas de políticas neoliberal do capitalismo global, produzindo instabilidade econômica, política e social, principalmente nos países do terceiro mundo. (GONÇALVES, 2002, p. 25 apud DELGADO, 2004, p. 67)

Para o autor citado, o Terceiro Setor apresenta como premissa básica, a equidade e a justiça social com as instituições democráticas. Como exemplo, menciona a Campanha "Ação contra a Fome, a Miséria e pela Vida", considerado um marco pela sua abrangência e poder de mobilização, dirigida pelo sociólogo Herbert de Sousa, o Betinho. Para tanto, Bava (2000) citando Betinho salienta que:

Vamos sonhar, pensar e praticar a democracia, cada um fazendo a sua parte, tomando iniciativa, pondo a sua própria capacidade a serviço de todos e, tomando a iniciativa, pondo a sua própria capacidade a serviço de todos e, com isso, exercendo o direito e o dever de cidadania. (BAVA, 2000, p. 55)

Sob esta perspectiva, Delgado (2004) acrescenta que até mesmo o Segundo Setor, que funciona com uma lógica diferente, que visa o lucro, a partir da década de 1990, encabeçou e dirigiu recursos para programas e projetos sociais, especialmente, por meio de suas fundações e institutos, sendo assim 
Juliane Sachser Angnes, Mábia Camargo, Luciano Ferreira de Lima \& Marcel Luciano mais uma opção de recursos para a área do Terceiro Setor.

Desta forma, surge no Segundo Setor, o conceito de responsabilidade social corporativa, embasado por Tachizawa (2007, p. 63), que enfatiza "o impacto das atividades das empresas para os agentes com as quais interagem (stakeholders): empregados, fornecedores, clientes, consumidores, colaboradores, investidores, competidores, governos e comunidade". Em complemento, este mesmo autor afirma que responsabilidade social se relaciona "à governança corporativa e à gestão empresarial, em questões ambientais e sociais, e são crescentemente mais relevantes para o êxito e a sobrevivência nos negócios." (Op. cit. , p. 64)

Assim, o Segundo Setor passou a utilizar o conceito de ética na responsabilidade social corporativa que, segundo Neto e Froes (2004), tem como objetivo desenvolver a sociedade e a comunidade a partir de novas inserções e parcerias envolvendo outros agentes, tais como empresas, ONGs, entidades filantrópicas, associações comunitárias e o próprio Estado. Neto e Froes afirmam:

\begin{abstract}
As ações de responsabilidade social corporativa buscam aprimorar as relações das empresas com seus diversos públicos, inseri-las devidamente no âmbito social das comunidades vizinhas e sobretudo, reforçar a atuação das ONGs, associações comunitárias, entidades filantrópicas e o governo local, seus principais parceiros. (NETO, FROES, 2004, p. 22)
\end{abstract}

Observa-se com este posicionamento que a responsabilidade social está relacionada com a consciência social e o dever cívico. Reflete a ação de uma empresa em prol da cidadania. A empresa que a pratica demonstra uma atitude de respeito e estímulo à cidadania corporativa; consequentemente existe uma associação direta entre o exercício da responsabilidade social e o exercício da cidadania empresarial (NETO, FROES, 2004).

Entretanto, o Terceiro Setor, nesta pesquisa representado pelas ONGs, apresenta muitas dificuldades como, por exemplo, o crescente número de organizações sem fins lucrativos, e consequentemente 0 aumento da "competitividade entre as ONGs". (BARREIRA, 2001 apud TACHIZAWA, 2007, p.155).

Além disso, nem todas as ONGs são estrategicamente ativas aliado ao fato de algumas delas apresentarem um perfil distante da realidade das 
instituições privadas, demonstrando em algumas situações para as Agências de Cooperação Internacionais, que elas não necessitem de recursos financeiros.

Muitas ONGs não pensam estrategicamente, considerando que o capital, definido por Camargo et al. (2001), em vez de fim em si mesmo, como é natural nas sociedades mercantis, passa a ser um meio, "um instrumento para a realização dos reais objetivos das entidades" (p. 59). E todas as ONGs necessitam deste instrumento para sua sustentabilidade e de seus trabalhadores. Não é porque elas apresentam um contexto sem fim lucrativo, que não necessitem dos recursos financeiros para sua sobrevivência.

Dessa forma, adota-se nesta pesquisa, a postura ativa na assessoria para elaboração de um plano de captação de recursos para ONGs, pois com a utilização deste instrumento, estas (as ONGs) podem tornar-se mais ativas, utilizando-se um modelo de gestão que sinalize ênfase estratégica na captação dos recursos financeiros, necessários à execução dos projetos sociais. Essa captação pode ocorrer por meio de várias fontes: pessoas físicas na forma de doações, bem como de parcerias específicas. (ANDRADE, 2002)

Para Armani (2003, p. 143), cresce a discussão sobre esse tema, "se avolumam as publicações sobre captação de recursos", isso porque as ONGs nunca irão se sustentar financeiramente sem uma proporção de recursos doados, essas organizações sempre irão depender de uma capacidade para obter receitas. A seguir apresentam-se algumas estratégias para captação de recursos diretamente vinculadas a ONGs.

\subsection{CAPTAÇÃO DE RECURSOS PARA ONGS}

No Brasil a captação de recursos é tida como um dos maiores desafios para as organizações do Terceiro Setor, devido ao grande crescimento e ao aumento da competitividade entre as próprias ONGs para obter parceiros e recursos. Neste caso, grande parte das ONGs obrigam-se a investir nas formas de captação de recursos que estimulem a contribuição de pessoas, do governo e da iniciativa privada. Portanto, acredita-se ser essencial que estas reconheçam a relevância em realizar-se um planejamento de ações de captação de recursos por meio de projetos próprios. (ADULIS, 2002) 
Juliane Sachser Angnes, Mábia Camargo, Luciano Ferreira de Lima \& Marcel Luciano

Na visão de Albuquerque (2006), a captação de recursos passou a ser um trabalho que ganhou muita visibilidade nas organizações do Terceiro Setor, com destaque para os anos 1990, quando as organizações perceberam a necessidade de investir nesta área, conforme anteriormente destacado.

Acredita-se que essa percepção está em boa parte relacionada ao crescimento do número entidades em todo o país. Segundo o estudo de Delgado "em 2004 havia no país aproximadamente 276 mil fundações e associações sem fins lucrativos" (p. 4). Com esse crescimento, a questão da sustentação em longo prazo dessas organizações tornou-se o principal desafio. Desde o seu surgimento as ONGs se mantinham por meio de recursos financeiros, humanos e materiais provindos de doações de Agências de Cooperação Internacional.

Entretanto, com a escassez dos recursos financeiros desde 2006, as ONGs, principalmente no que diz respeito a sua sustentabilidade se obrigaram a "entrar no jogo" em termos financeiros. Muitas organizações que começaram com esforços pessoais e apoio inicial de doadores estrangeiros, públicos ou privados, atualmente, se encontram desenvolvidas em maior escala e complexidade, com graves problemas de sobrevivência, isso porque "cada vez mais organizações disputam uma fatia do mesmo bolo que se encontra cada vez menor" (ISCHOPE, 2005, p. 106).

No caso da ONG estudada, a sua principal fonte de captação de recursos eram as Agências Internacionais de Cooperação Não Governamentais. Tais agências também eram responsáveis pela maioria dos recursos das ONGs, tornando-se fundamentais para a sua existência e crescimento. Entretanto, com a mudança de foco dessas agências, faz-se necessário encontrar novas fontes de recursos. Segundo Tachizawa, a captação de recursos pode ser conceituada como:

Busca de recursos (não exclusivos, mas predominantemente financeiros) como forma de atingir a missão de uma entidade, implementando programas e projetos de organizações do Terceiro Setor. Conjunto de técnicas destinadas a organizar e a potencializar a busca de recursos. (TACHIZAWA, 2007, p. 303)

Com base nesta citação, entende-se que a captação de recursos seja capacidade de obter receitas. Ainda Armani diz que: 
Captação de recursos na ONG " $X$ ":

Uma experiência prática interdisciplinar entre profissionais administração e secretariado

executivo

As ONGs podem obter receitas próprias de forma regular por meio de contribuição de sócios e rede de amigos, prestação de serviços de forma remunerada, venda de produtos, ou ainda por meio de fontes de financiamento públicas, privadas e não governamentais nacionais e internacionais".(ARMANI, 2003, p.143)

A partir da citação, observa-se que a captação de recursos não diz respeito exclusivamente à receita (dinheiro), não se refere somente a obtenção do mesmo, entretanto, pode-se definir também como "o estabelecimento e gerenciamento de relacionamentos com pessoas e organizações que podem ter interesse na organização" (ADULIS 2002, apud TACHIZAWA, 2007, p. 34). Desta forma, a partir da visão da autora citada, entende-se que essas organizações necessitam captar recursos que financiem as atividades e projetos desenvolvidos. Para tanto, precisam desenvolver atividades constantemente para a captação de recursos, tendo como foco atingir a missão da entidade.

Outra dificuldade apontada por Drucker (1997) para a captação de recursos é que muitas pessoas pensam que o dinheiro é a solução de todos os problemas. Na visão do autor, isso é um engano, pois o objetivo "não é sair em busca de qualquer doação em dinheiro, mas ideal é conseguir um público que se mobilize com a organização e contribua por meio de recursos financeiros, humanos e materiais" (p. 37).

No que se refere aos recursos públicos, de acordo com Albuquerque (2006), as organizações do Terceiro Setor podem vir conquistar o apoio e financiamento de suas atividades pelo Estado. Além de captar recursos junto ao Estado (Primeiro Setor), as organizações, desde 1996, podem receber a doação de recursos de pessoas físicas. As pessoas físicas podem contribuir doando dinheiro, produtos de higiene e limpeza e outros materiais. Além disso, podem colaborar com o trabalho voluntário nas ONGs.

Quando se trata de pessoas físicas, Albuquerque (2006) e Drucker (1997) defendem que passa a ser necessário reconhecer os diferentes perfis de colaboradores para a captação de recursos. Para esses autores, os doadores possuem perfis diferentes, portanto, cabe à organização utilizar a estratégia que mais se adequar ao seu perfil. Por exemplo, existem pessoas que se mobilizam quando acontecem grandes calamidades, e mesmo não sendo sócios da organização estão aptas a colaborar; há aquelas, ainda, que só se mobilizam por 
Juliane Sachser Angnes, Mábia Camargo, Luciano Ferreira de Lima \& Marcel Luciano campanhas desenvolvidas pelas rádios e TV (como o "Teleton" e o "Criança Esperança"), que, utilizando-se da afetividade e emotividade do ouvinte ou do telespectador, estimulam-nos a colaborar com as organizações. (ALBUQUERQUE, 2006)

Outra forma de se captar recursos pode ser por meio das doações de pessoas jurídicas, que podem ser as empresas ou fundações (Segundo Setor). Porém, esse tipo de doação exige que a organização beneficiada entregue uma declaração ao doador comprometendo-se a aplicar todos os recursos recebidos para a realização dos objetivos da entidade, e de não bonificar nenhum dirigente ou associado, devendo identificar a pessoa responsável pelo seu cumprimento. (ALBUQUERQUE, 2006 ; DRUCKER, 1997)

Basicamente, conforme Abumanssur e Hardwick (2011) existem três principais fontes de renda identificadas pela maioria das organizações sem fins lucrativos: a) recursos governamentais; b) renda gerada pela venda de serviços (por exemplo, consultorias) ou produtos (camisetas, chaveiros, agendas etc.); e, c) recursos captados por meio de doações (de indivíduos ou instituições).

Assim, por meio desta breve explanação sobre algumas formas de captação de recursos diagnosticaram-se algumas das fontes existentes que podem ser destinadas às ONGs. Cruz e Straviz (2003, p. 77), acrescentam que "[...] não se deve esperar recursos de uma única fonte, pois corre-se o risco de essa fonte deixar de contribuir". Por outro lado, a visualização das diferentes possibilidades de captação contribui para destacar o quanto o planejamento de formas para conquistar a atenção destas fontes exige que a organização se preocupe com um plano a ser elaborado e seguido.

\section{METOdOLOGIA DA PESQUISA}

Este estudo tratou de uma pesquisa qualitativa destinada à proposição de planos, o qual se propôs a descrever, a partir da realidade local, uma experiência prática na elaboração de um plano para captação de recursos destinado a uma ONG, de porte médio, localizada na cidade de Guarapuava-PR.

Nesse sentido a pesquisa em campo foi realizada no período de 2/2/2011 a $2 / 10 / 2011$, totalizando dez meses, em formato de quatro horas semanais, 
sendo realizada em parceria por professores dos Cursos de Administração e Secretariado Executivo da Universidade Estadual do Centro Oeste do Paraná. Assim, ao todo, a pesquisa em campo abrangeu um total 160 horas que foram registradas em diário de campo específico.

Para tanto, a construção da primeira etapa da pesquisa - 2/2/2011 a 2/4/2011 - objetivou pesquisar as principais estratégias de captação de recursos financeiros utilizadas pelas ONGs no Brasil. Nesta etapa, optou-se em utilizar como técnica central a pesquisa bibliográfica em autores que tratam especificamente desta temática. Foram consultados, ainda, artigos científicos em sites de pesquisa (ScIELo entre outros) e teses no banco da Coordenação de Aperfeiçoamento de Pessoal de Nível Superior (Capes).

Por sua vez, a segunda etapa da pesquisa - 3/4/2011 a 3/6/2011 - visou diagnosticar a situação da ONG " $X$ "; no que se refere à captação de recursos financeiros. Nesta etapa, utilizaram-se como técnicas centrais a pesquisa documental em relatórios financeiros dispostos nos arquivos, a observação participante e reuniões com o dirigente e cinco colaboradores (funcionários).

Na terceira etapa da pesquisa - 4/6/2011 a 2/10/2011 - após as coleta dos dados, elaborou-se em parceria, uma proposição de planos (modelo) que atendesse aos interesses da organização em estudo. Nesta etapa utilizou-se a técnica de pesquisa caracterizada como descritiva que objetivou propor estratégias de captação de recursos para essa organização. Tal plano seguiu os pressupostos teóricos pesquisados em Fontanella (2008), Ashoka e McKinsey (2009), Falcão (2002) apud Andrade (2002, p. 63).

Cabe salientar que esta proposição de planos pautou-se na hipótese de que a ONG " $X$ " poderá se desenvolver, no futuro, por meio de uma captação de recursos estruturada. Desta maneira, por limitações de espaço, não houve como detalhar neste artigo os modelos elaborados minuciosamente. 
Juliane Sachser Angnes, Mábia Camargo, Luciano Ferreira de Lima \& Marcel Luciano

\section{ANÁLISE E DISCUSSÃO DOS RESULTADOS}

\subsection{A ONG "X": CONTEXTUALIZAÇÃO}

A ONG "X" foi fundada na cidade de Guarapuava em 1986 sob a forma jurídica de Fundação é e regida por estatuto próprio. Neste sentido, Stefano (2010) apresenta que esta ONG foi constituída baseada na ideia da busca de um modelo de desenvolvimento agrícola que respeitasse o meio ambiente, objetivando apoiar pequenos agricultores da região nas áreas de produção, beneficiamento, comercialização e associativismo.

Dessa forma, por se tratar de uma instituição sem fins lucrativos, a ONG " $X$ " não comercializa ou fabrica produtos. Apenas presta serviços, tais como: a) realização de pesquisas e experimentação em desenvolvimento rural sustentável; b) dá assessoria em determinadas áreas, como por exemplo, agroecologia, economia solidária, sociologia, comercialização e administração rural; c) trabalha com divulgação de tecnologias, políticas de desenvolvimento e formas de organização, direcionadas à agricultura familiar; d) formula programas de capacitação profissionais a agricultores e líderes rurais.

Quanto à organização administrativa, a ONG " $X$ " não dispõe de departamentos específicos, ficando a cuidado dos colaboradores realizarem atividades em conjunto. Nesse sentido, a Fundação possui apenas dois colaboradores que são registrados (Contador e Engenheiro Agrônomo) somandose a mais quatro colaboradores voluntários (Presidente, Assessor de Coordenação, Financeiro e Secretária). Todos os colaboradores possuem nível superior e $50 \%$ deles atuam na organização há mais de três anos. (STEFANO, 2010)

No que se refere à estrutura física, a Fundação está instalada em uma área de 18 alqueires. Sua área construída abarca 771,46 metros quadrados, a qual é dividida em dois pavimentos. Nessa estrutura, a ONG " $X$ " dispõe de centro de formação, local próprio para hospedagem e alimentação, sala de jogos, sala de reuniões, área administrativa, cozinha, refeitórios, biblioteca, arquivos, sala de treinamento e sala de espera. Além disso, há um amplo espaço externo arborizado com campo de futebol, jardim, estacionamento e estufa. Cabe 
Captação de recursos na ONG " $X$ ":

Uma experiência prática interdisciplinar entre profissionais administração e secretariado executivo

destacar ainda, que a ONG " $X$ " dispõe de sistema de energia solar e utiliza água de fonte natural.

\subsection{O PLANO DE CAPTAÇÃO DE RECURSOS PARA ONG " $X$ ": DESCREVENDO A EXPERIÊNCIA PRÁTICA}

Na ONG " $X$ ", as fontes de recursos são basicamente de duas origens diferenciadas: a) recursos obtidos com financiadores estrangeiros; b) parcerias com o Ministério do Desenvolvimento Agrário. Entretanto, com a proposição de um plano de captação de recursos para a ONG " $X$ " acredita-se que se poderá ampliar as opções desta ONG no que se refere às fontes financiadoras, principalmente, ao demonstrar-se por meio de projetos que os financiadores de Guarapuava poderão obter um retorno social em relação ao que investiram.

Dessa forma, o grupo proponente do projeto adotou uma postura que a estrutura de um plano de captação de recursos varia de acordo com os objetivos de cada organização, mas basicamente deve apresentar os seguintes itens, descritos de acordo com os estudos de Andrade (2002, p. 120).

\subsubsection{Autoanálise}

Neste ciclo identificam-se as principais "Oportunidades e Ameaças no ambiente externo capazes de terem um impacto sobre as atividades de captação de recursos da organização". (ANDRADE, 2002, p. 121). Na ONG "X" utilizou-se inicialmente a metodologia Fofa (uma análise de quatro itens - Fortalezas e Fragilidades internas que dizem respeito a questões específicas de cada organização, os outros dois - Oportunidades e Ameaças que avaliam as forças existentes no ambiente externo capazes de afetar uma variedade de grupos diferentes. (ABUMANSSUR; HARDWICK, 2011)

Dessa maneira, durante as reuniões com a equipe de colaboradores, foram diagnosticados os principais pontos fortes e as fragilidades da ONG " $X$ ", bem como todas as potenciais oportunidades e ameaças na região de Guarapuava, traçando metas a curto, médio e longo prazo. Durante esse período utilizou-se uma técnica denominada "Brainstorming" como forma de sistematização das informações. Foram realizadas aproximadamente oito reuniões com uma média de tempo de duas horas para cada reunião. 
Juliane Sachser Angnes, Mábia Camargo, Luciano Ferreira de Lima \& Marcel Luciano

O grupo apontou como ponto falho o fato de a ONG " $X$ " não ter um planejamento no que se refere à captação de recursos e o aspecto da organização ter dificuldades em trabalhar com metas a longo prazo. Em contraponto, esse mesmo grupo apontou como pontos fortes o fato de apresentarem um controle rígido dos gastos, mas devido à oscilação dos recursos terem dificuldades em trabalhar com o remanejamento do orçamento. O relato confirma esta questão: "todos os projetos têm orçamentos próprios, porém não sabemos como propor custos e gastos no que se refere ao ato de captar um recurso diretamente com terceiro, acho que o problema está no maximizar". (DIÁRIO DE CAMPO, 2011)

Tais fatores apontados direcionaram o grupo de pesquisadores ao aspecto "planejamento", de forma a auxiliar os colaboradores da ONG "X".

\subsubsection{Planejamento}

Uma vez sistematizadas as informações das reuniões por meio da análise Fofa na captação de recursos para a ONG "X", elaborou-se um planejamento visando executar esta captação inspirados por uma visão daquilo que os recursos permitirão uma vez captados. Dito de outra forma, trabalhar com metas a longo prazo. Neste processo foram acertados os detalhes quanto a quem, quando, onde e como cada iniciativa será realizada.

A realização desta etapa foi essencial porque obrigou os colaboradores a pensar e discutir e construir os três " $\mathrm{C}$ " (clareza, consenso e compromisso) abrindo o caminho para um trabalho mais centrado. Neste sentido, a proposição de um plano de captação de recursos para a ONG " $X$ " ficou com a estrutura básica/resumida diagramada da seguinte forma a ser adotada em cada projeto da instituição:

\section{Quadro 1: Plano de captação de recursos resumido para ONG "X"}

\begin{tabular}{|l|l|}
\hline \multicolumn{1}{|c|}{ ITEM } & \multicolumn{1}{|c|}{ DETALHAMENTO/EXECUÇÃO } \\
\hline $\begin{array}{l}\text { Apresentação da } \\
\text { organização }\end{array}$ & $\begin{array}{l}\text { Detalhar o histórico e conquistas das organizações de } \\
\text { assistência social. }\end{array}$ \\
\hline
\end{tabular}


Captação de recursos na ONG " $X$ ": Uma experiência prática interdisciplinar entre profissionais administração e secretariado executivo

\begin{tabular}{|c|c|}
\hline Apresentação do serviço & $\begin{array}{l}\text { Apresentar as características do serviço de assistência } \\
\text { social que será prestado e impacto na comunidade } \\
\text { atendida. }\end{array}$ \\
\hline Análise do mercado & Realizar a justificativa do projeto. \\
\hline Marketing & $\begin{array}{l}\text { Detalhar os canais de distribuição, preço/custo e } \\
\text { comunicação. }\end{array}$ \\
\hline Planejamento financeiro & $\begin{array}{l}\text { Realizar a análise da relação custo/benefício e viabilidade } \\
\text { do serviço. }\end{array}$ \\
\hline Equipe gerencial & Apresentação da equipe e colaboradores externos. \\
\hline Riscos e oportunidades & $\begin{array}{l}\text { Antecipação dos eventuais problemas e propostas de } \\
\text { solução. }\end{array}$ \\
\hline $\begin{array}{l}\text { Plano de implantação e } \\
\text { cronograma }\end{array}$ & $\begin{array}{l}\text { Detalhamento do projeto com a especificação das } \\
\text { principais atividades, bem como os respectivos prazos e } \\
\text { responsáveis. }\end{array}$ \\
\hline
\end{tabular}

Fonte: Os autores (2011) adaptado para a ONG "X" a partir de Maximiano (2002).

No item que se refere à apresentação da organização, conforme o Quadro 1 , a equipe participou ativamente no processo de entender a missão da organização, o trabalho que esta ONG desenvolve, como o faz, o público-alvo que se beneficia e os resultados de seu trabalho. Durante as reuniões em grupo, buscou-se responder descritivamente as seguintes questões: a) Por que a organização necessita captar recursos? b) Por que precisa mais recursos do que o que já recebe? c) Por que instituições ou indivíduos doariam recursos a ela?

Por meio das respostas dessas questões, pode-se compreender o projeto que a ONG " $X$ " desenvolve ajustando a proposta do plano de captação de recursos aos objetivos dos potenciais doadores/investidores. Esta estratégia de apresentação da organização exigiu bastante criatividade do grupo executor em parceria com os colaboradores da ONG " $X$ ". De acordo com o discurso durante as discussões sobre o plano um funcionário salientou:

Nunca antes na vida havíamos pensado em elaborar um planejamento detalhado para a captação de recursos (sic) a gente somente fazia, preparava projetos para estrangeiros. Nunca pensamos em potenciais doadores em nossa região. (DIÁRIO DE CAMPO, 2011) 
Juliane Sachser Angnes, Mábia Camargo, Luciano Ferreira de Lima \& Marcel Luciano

No que se referem aos Riscos e Oportunidades apresentados no Quadro 1 realizou-se para a ONG " $X$ " uma pesquisa dos potenciais investidores/doadores. Após isso, separaram-se os prováveis investidores/doadores por meio de categorias: vínculo/interesse/capacidade. No ato dessa seleção, adotou-se o critério do investidor/doador sob três aspectos: vizinhança, porte da empresa e afinidade com a ação social. Realizada esta etapa determinou-se a melhor forma de abordar as empresas/pessoas, descobrindo quais são seus interesses.

Esta ação foi embasada no sistema de mensuração de desempenho balanced scorecard (BSC) que visa propor os objetivos de curto e longo prazo por meio da utilização de medidas financeiras e não financeiras, indicadores de tendências (leading) e medidas de desempenho (lagging), alinhando as perspectivas interna e externa (KAPLAN \& NORTON, 1997; 2004; REZENDE; 2003; HERRERO FILHO; 2005).

Neste sentido, o BSC visa medir o desempenho organizacional sob quatro perspectivas equilibradas: financeira, do cliente, dos processos internos da empresa e do aprendizado e crescimento, orientando e definindo para os gerentes, empregados, investidores e clientes qual o foco e esforços da organização.

De acordo com Santos et al. (2008) os indicadores do projeto podem ser de acordo com o ângulo que se quer avaliar: eficiência (boa utilização dos recursos), eficácia (alcance dos resultados previstos), efetividade (benefícios ou mudanças gerado) ou impacto (influência em outras áreas). Desta forma, os autores acrescentam que:

Um projeto durante seu ciclo de vida pode ter vários indicadores, de acordo com sua fase, interesse dos gestores, grau de conhecimento da situação, nível de detalhes, em resumo, eles devem ser definidos de forma a traduzir os objetivos e resultados do projeto, dos gestores e financiadores. (SANTOS et al., 2008, p. 16)

Nesse sentido, foram elaborados quadros para todos os projetos da ONG "X". Entretanto, por questões de espaço, apresenta-se o Quadro 2 como exemplificação de um dos projetos desenvolvidos pela ONG. 


\section{Quadro 2: Indicadores de BSC para o Projeto MDA Plantas Medicinais}

\begin{tabular}{|c|c|c|c|}
\hline \multirow[b]{2}{*}{ Perspectiva } & \multirow[b]{2}{*}{$\begin{array}{l}\text { Objetivos } \\
\text { Estratégicos }\end{array}$} & \multicolumn{2}{|c|}{ Indicadores Estratégicos } \\
\hline & & $\begin{array}{l}\text { Indicadores de } \\
\text { Resultados }\end{array}$ & $\begin{array}{l}\text { Indicadores de } \\
\text { Tendência }\end{array}$ \\
\hline Doador & $\begin{array}{l}\text { a) Aumentar o } \\
\text { percentual de } \\
\text { metas atingidas } \\
\text { no projeto. }\end{array}$ & \begin{tabular}{|l|} 
a) Nível de satisfação. \\
b) Retenção do \\
doador. \\
c) Volume metas \\
alcançadas.
\end{tabular} & $\begin{array}{l}\text { a) Variação \% de } \\
\text { satisfação com o projeto } \\
\text { em relação ao anterior. } \\
\text { b) Variação \% de } \\
\text { satisfação do doador } \\
\text { com os resultados do } \\
\text { projeto. } \\
\text { c) Variação \% de metas } \\
\text { concluídas }\end{array}$ \\
\hline Beneficiários & $\begin{array}{l}\text { a) Identificar o } \\
\text { nível de } \\
\text { aproveitamento } \\
\text { dos agricultores } \\
\text { que plantam as } \\
\text { ervas } \\
\text { medicinais. }\end{array}$ & $\begin{array}{l}\text { a) Nível de satisfação. } \\
\text { b) Nível de apoio } \\
\text { familiar. }\end{array}$ & $\begin{array}{l}\text { Aumento } \% \text { de } \\
\text { agricultores satisfeitos } \\
\text { de acordo com as etapas } \\
\text { de implantação do } \\
\text { projeto de plantas } \\
\text { medicinais. }\end{array}$ \\
\hline \begin{tabular}{|l|} 
Funcionários e \\
voluntários
\end{tabular} & $\begin{array}{l}\text { a) Identificar o } \\
\text { nível de } \\
\text { satisfação. }\end{array}$ & a) Nível de satisfação. & $\begin{array}{l}\text { a) Proposição de um } \\
\text { novo projeto. }\end{array}$ \\
\hline
\end{tabular}

Fonte: Os autores (2011), adaptado para ONG "X", a partir de Kaplan e Norton (1997).

Além disso, o grupo preparou uma sugestão de formas de propaganda para a ONG " $X$ ", ou seja, trabalhou-se com a perspectiva de que não basta simplesmente solicitar recursos aos possíveis investidores/doadores; torna-se necessário desenvolver o interesse deles, por meio da elaboração em informativos, panfletos, cartas ao editor do jornal local, discursos em público, estandes em eventos comunitários. Ou seja, acredita-se que as oportunidades em Guarapuava são inúmeras e a maioria delas não custa muito. O objetivo central da proposta de propaganda pensada pela equipe foi para que as pessoas sintam que seu envolvimento pode fazer uma diferença útil ao trabalho de uma organização essencial para a sociedade.

Dessa forma, a ONG " $X$ " poderá planejar uma propaganda social como retorno ao seus investidores/doadores levando em consideração as duas formas a seguir: 
Juliane Sachser Angnes, Mábia Camargo, Luciano Ferreira de Lima \& Marcel Luciano

Quadro 3: Formas de comunicação/divulgação propostas para a ONG "X"

\begin{tabular}{|l|l|}
\hline \multicolumn{1}{|c|}{ ASPECTOS } & \multicolumn{1}{c|}{ PRINCIPAIS QUESTIONAMENTOS } \\
\hline Relatórios de & $\begin{array}{l}\text { 1) A organização publica relatórios? } \\
\text { atividades }\end{array}$ \\
& $\begin{array}{l}\text { 2) Qual sua periodicidade? } \\
\text { 3) Estão disponíveis ao público? } \\
\text { 4) Contempla avaliação de desempenho? }\end{array}$ \\
\hline $\begin{array}{l}\text { Parceria com mídia } \\
\text { aberta }\end{array}$ & $\begin{array}{l}\text { 1) Qual a mídia mais adequada para a divulgação? } \\
\text { 2) É possível estabelecer parceria com empresários } \\
\text { de comunicação? } \\
\text { 3) Que tipo de informação será disponibilizada? } \\
\text { 4) É possível ter um profissional (voluntário ou } \\
\text { contratado) de comunicação orientando o } \\
\text { processo? }\end{array}$ \\
\hline
\end{tabular}

Fonte: Os autores (2011).

Também foi elaborado um Planejamento Financeiro detalhado com modelos de planilhas que poderão ser atualizadas via sistema on-line e mantidas em arquivos para acompanhamento de todos os envolvidos na ONG " $X$ ". Os dados financeiros não foram autorizados para publicação externa. Entretanto, o Quadro 4 apresenta as questões que nortearam a elaboração do plano financeiro da ONG " $X "$ ":

\section{Quadro 4: Planejamento Financeiro para Captação de Recursos da ONG " $X$ "}

\begin{tabular}{|l|l|}
\hline \multicolumn{1}{|c|}{ ASPECTOS } & \multicolumn{1}{c|}{ PRINCIPAIS QUESTIONAMENTOS } \\
\hline Recursos disponíveis & $\begin{array}{l}\text { 1) Qual o montante necessário? } \\
\text { 2) Quais são as possíveis fontes de financiamento? } \\
\text { 3) Onde os recursos do exercício anterior foram } \\
\text { investidos? } \\
\text { 4) De onde vieram os recursos do exercício anterior? }\end{array}$ \\
\hline Sustentabilidade & $\begin{array}{l}\text { 1) A organização é autossustentável? } \\
\text { 2) Caso não seja, pode tornar-se? Como? } \\
\text { 3) Quais são as parcerias vitais? } \\
\text { 4) Qual é a projeção financeira para os próximos três } \\
\text { anos? }\end{array}$ \\
\hline Fluxo de caixa & $\begin{array}{l}\text { 1) A organização pode cumprir as obrigações } \\
\text { financeiras a qualquer momento? }\end{array}$ \\
\hline Auditoria & 1) É necessário auditar as informações financeiras? \\
\hline
\end{tabular}

Fonte: Os autores (2011).

Assim, seguindo a proposta de Dimenstein (2005) no que se refere à captação de recursos, a equipe elaborou: a) definição exata da verba necessária 
para realizar a ação; b) pesquisa dos potenciais doadores; c) levantamento dos contatos no entorno da entidade; d) confecção de uma lista ou banco de dados; e) elaboração e sugestão de proposta bem estruturada, com orçamento; f) montagem de uma apresentação sobre a proposta; g) modelo de carta de agradecimento; j) planilha de prestação de contas.

Torna-se relevante salientar que esse projeto de captação de recursos não deve ser considerado como um receituário único, padrão; ao contrário, deve ser considerado como um mero referencial de gestão, que é dinâmico e adaptável de acordo com as singularidades de cada organização do Terceiro Setor (TACHIZAWA, 2007).

Para os pesquisadores, existe a viabilidade de análise sobre a implantação nos anos de 2012/2013, de acordo com a disposição funcional da ONG " $X$ " que passará nesses anos por uma readequação de sua estrutura interna.

\section{CONSIDERAÇÕES FINAIS}

Após a elaboração e sugestão do plano de estratégias de captação de recursos para a ONG " $X$ ", realizada pelos pesquisadores e parceria com os colaboradores desta, espera-se que este possa ser implantado nos anos de 2012/2013, e que essas estratégias possam ser aplicadas na prática, auxiliando a instituição na sua sustentabilidade futura.

Sugestionou-se para a ONG " $X$ " a implantação/criação de um departamento exclusivo à captação de recursos contendo um profissional de gestão, um de marketing e uma assessoria executiva (contratados). Embora essa alternativa (a criação do departamento) não seja financeiramente viável para a ONG " $X$ " no momento, existem demandas urgentes para a contratação desses profissionais, e que estes foquem seus esforços diretamente à captação de recursos.

$\mathrm{Na}$ realidade investigada, observou-se que ONG " $X$ " utiliza apenas a promoção de eventos como uma forma divulgar e captar recursos. Observou-se que os eventos são vistos como formas eficientes de divulgação e ao mesmo tempo de captação de recursos, conforme demonstraram os relatos dos 
Juliane Sachser Angnes, Mábia Camargo, Luciano Ferreira de Lima \& Marcel Luciano colaboradores durante as reuniões. Porém, não são apenas eventos que podem ser fontes de recursos. A organização pesquisada não possui sequer meios específicos de comunicação para divulgação de sua atuação, prestação de contas ou relacionamento com as fontes financiadoras.

Neste sentido, vale destacar que o desafio hoje está não somente em captar recursos, mas em manter as fontes já conquistadas. No estudo realizado concorda-se com Drucker (1997), quando este afirma não ser mais suficiente captar dinheiro, mas, sim, pessoas comprometidas com a causa da instituição.

Por meio da observação participante, foi possível descrever os resultados do estudo de campo, concluindo que as assessorias (profissionais de secretariado) podem atuar em parceria com os administradores de forma direta em organizações do Terceiro Setor. Neste ínterim, acredita-se que pesquisa realizada interdisciplinarmente entre os profissionais de secretariado e administradores seja uma relação fundamental da gestão de qualquer organização. Confirmando este aspecto, Nonato Júnior (2009) apresenta que:

As Ciências da Assessoria são demarcadas por meio da Assessoria e sua múltiplas relações interdisciplinares [...] É preciso compreender que as assessorias estão presentes em toda parte, desde a gestão organizacional até as práticas dos trabalhos em campo. Logo, estão constantemente se relacionando com outras áreas, seja no domínio técnico, tático, executivo, estratégico, investigativo. [...] Com a Administração, essas assessorias pesquisam e desenvolvem ideias que fazem avançar o trabalho dos gestores e das organizações. (NONATO JÚNIOR, 2009, p. 154)

Assim, durante a execução de todo projeto em si na ONG " $X$ ", observouse a relevância desta parceria posta em prática, isto porque, para se identificar e apurar a realidade deste contexto, houve a necessidade constante de diálogo, negociação, leituras, discussões, escala de poderes dividida entre ambas as áreas. Assim, a partir dos resultados deste estudo, percebeu-se que o trabalho em conjunto e interdisciplinar auxilia para "derrubar" o mito de que uma área seja "melhor que a outra", mas sim, que a relação entre ambas deva ser de "parceria".

Dessa maneira, observou-se que a parceria estabelecida pelas duas áreas de conhecimento - administração e ciências da assessoria - permitiu a cada uma delas trabalhar de forma concentrada em seus objetivos específicos; mas quando 
houve a junção de tais objetivos, estes resultaram numa melhoria para a ONG "X": o plano de captação de recursos. Assim, observou-se o rompimento de várias resistências, de modo a se promover a troca de conhecimentos e a integração de novas metodologias para ambas as áreas.

\section{REFERÊNCIAS}

ABUMANSSUR, H. O; HARDWICK, M. Captação de recursos: da teoria à prática. 2011 Disponível em: http://www.sosma.org.br/files/pFiles/6.pdf Acesso em: 30 jan. 2011.

ABONG. ONGs no Brasil : perfil das associadas à Abong: tabelas orçamento. São Paulo: 2010. Disponível em: www.abong.org.br Acesso em: 20 jul. 2011.

ADULIS, D. O Papel da comunicação na captação de recursos. 2002. Disponível em: www.rits.org.br Acesso em: 4 set. 2011.

ALBUQUERQUE, A. C. C. Terceiro Setor: história e gestão de organizações. São Paulo: Summus, 2006.

ANDRADE, M. G. V. Organizações do Terceiro Setor: estratégias de captação de recursos junto às empresas privadas. 2002. Dissertação (Mestrado em Engenharia de Produção) - Universidade Federal de Santa Catarina, Florianópolis.

ARMANI, D. $\mathbf{O}$ desenvolvimento institucional como condição de sustentabilidade das ONGs no Brasil. 2003, 10 p. Disponível em:

www.aids.gov.br/final/biblioteca/sustenta/desenvol.htm Acesso em: 26 maio 2011

ASHOKA. Empreendedores Sociais, McKinsey \& Company. Negócios sociais sustentáveis: estratégias inovadoras para o desenvolvimento social. São Paulo: Petrópolis, 2009. 
Juliane Sachser Angnes, Mábia Camargo, Luciano Ferreira de Lima \& Marcel Luciano

BAVA, S. C. O Terceiro Setor e os desafios do estado de São Paulo para o século XXI. In: Cadernos Abong. ONG, identidades e desafios atuais. São Paulo: Autores Associados, 2000.

CAMARGO, M. F. et al. Gestão do Terceiro Setor no Brasil. São Paulo: Futura, 2001.

CRUZ, C.; ESTRAVIZ, M. Captação de diferentes recursos para organizações sem fins lucrativos. São Paulo: Global, 2003.

CURY, R. R. Marketing e comunicação para o terceiro setor. Rio de Janeiro: 1999.

DELGADO, M. V M. O Terceiro Setor no Brasil: uma visão histórica. Revista Espaço Acadêmico número 37, junho de 2004, ano IV. Disponível em: http://www.espacoacademico.com.br Acesso em: 23 fev. 2011.

DIMENSTEIN, G. Captação de recursos para ONGs depende de planejamento e dedicação. Disponível em: <http://www1.folha.uol.com.br> . Acesso em: 13 ago.2011.

DRUCKER, P. F. Administração de organizações sem fins lucrativos: princípio e práticas. 4 ed. São Paulo: Pioneira, 1997.

FARIAS, V. D. Responsabilidade social na prática: a história e realizações. Caxias do Sul, RS : Faculdade Nossa Senhora de Fátima, 2008.

FERNANDES, R. C. Privado porém público: o Terceiro Setor na América Latina. 2 ed. Rio de Janeiro: Relume/Dumaré, 1994.

FONTANELLA, L. Sustentabilidad em Las Organizaciones Sin Fines Lucrativos de Lucro. Global Philantrophy. Synergos, 2008. Disponível em: http://www.synergos.org/knowledge/00/sustentabilidad.htm Acesso em: 10 nov. 2011.

GERÊNCIA DE ESTUDOS SETORIAIS (GESET). Terceiro Setor e o desenvolvimento Social. Disponível em:http://www.bndes.gov.br. Acesso em: 30 mar. 2010. 
GIFE. Investimento social privado no Brasil: perfil e catálogo dos associados GIFE. 2011.

GONH, M. G. Os sem-terra, ONGs e cidadania. 2 ed. São Paulo: Cortez, 2000. HERRERO FILHO, E. BSC e a gestão estratégica. Rio de Janeiro: Campus, 2005.

KAPLAN, R. S.; NORTON, D. P. A estratégia em ação: balanced scorecard. 11 ed. rev. Rio de Janeiro: Elsevier, 1997.

Mapas Estratégicos: convertendo ativos intangíveis em resultados tangíveis. 3 ed. São Paulo: Campus, 2004.

MAXIMIANO, A. C. A. Administração de projetos: como transformar ideias em resultados. São Paulo: Atlas, 2002.

NETO, F. P. M., FROES, C. Gestão da responsabilidade social corporativa: o caso brasileiro. 2 ed. Rio de Janeiro: Qualitymark, 2004.

NONATO JÚNIOR, R. Epistemologia e teoria do conhecimento em secretariado executivo: a fundação das Ciências da Assessoria. Fortaleza: Expressão Gráfica, 2009.

REZENDE, J. F. C. Balanced scorecard e a gestão do capital humano: alcançando a performance balanceada na economia do conhecimento. 2 ed. Rio de Janeiro: Elsevier, 2003.

RITS. Rede de informação para o terceiro setor. Disponível em: www.rits.org.br. Acesso em 19 ago.2011.

ROTHGIESSER, T. L. Sociedade civil brasileira e o Terceiro Setor. Disponível em: http://www.terceirosetor.org.br/ Acesso em: 20 mar. 2011.

SANTOS, N. C. dos; SUBLABAN, C. S. Y.; NETO, M. S.; GIULIANI, A. C.; SPERS, V. R. E. Captação de recursos financeiros em organizações sem fins lucrativos: a utilização de indicadores de gestão para os doadores e beneficiários dos projetos sociais. Revista de Gestão USP, São Paulo, v. 15, n. especial, p. 75-91, 2008.

STEFANO, S. (Org.) 0 caso da Fundação "X". Maringá: Unicopore, 2010. 
Juliane Sachser Angnes, Mábia Camargo, Luciano Ferreira de Lima \& Marcel Luciano

TACHIZAWA, T. Organizações não governamentais e Terceiro Setor: criação de ONGs e estratégias de atuação. São Paulo: Atlas, 2007.

Data do recebimento do artigo: 04/05/2011

Data do aceite de publicação: 20/08/2011 